\title{
Editorial
}

\section{Saúde mental, desenvolvimento e pobreza}

Existem atualmente duas tendências opostas na psiquiatria mundial. De um lado está o interesse pelos estimulantes avanços biológicos, como a pesquisa do genoma humano. Cada vez mais jovens psiquiatras, especialmente no Reino Unido, dedicam-se à pesquisa de determinantes biológicos para a saúde mental precária. De outro, discutivelmente menos influente, está a "escalada" da teoria e prática desenvolvimentista, resultante do fracasso do desenvolvimento econômico nacional de "beneficiar financeiramente" boa parte da população pobre de países em desenvolvimento. Profissionais especialistas em desenvolvimento, e até mesmo economistas, estão cada vez mais interessados em estudar o impacto das relações sociais sobre o desenvolvimento. Alguns psiquiatras hoje em dia desenvolvem trabalhos que ganham projeção a respeito da grande valia do capital social* e de seu papel no desenvolvimento econômico.

Esses psiquiatras têm muito a oferecer à teoria e à prática desenvolvimentista, devido ao seu conhecimento do ônus decorrente de relações sociais pobres e frágeis em termos de uma saúde mental precária e pelo fato de poderem indicar o caminho para intervenções potencialmente eficazes voltadas ao fortalecimento dessas relações sociais. À medida que os psiquiatras aprenderem a se comunicar em "linguagem desenvolvimentista", eles passarão a exercer um importante papel. Embora a ênfase atual sobre o capital social no desenvolvimento seja criticada por negligenciar as relações econômicas (de poder) e por dar importância excessiva às relações sociais, ela permite que a saúde mental esteja no centro das atenções como sendo um resultado importante das relações sociais. Está aí a oportunidade para que os psiquiatras lancem mão de sua influência.

As atuais tendências desenvolvimentistas, resumidas acima, são impulsionadas pela reconhecida necessidade de reduzir a pobreza. A associação entre pobreza e saúde mental em países em desenvolvimento é hoje bem demonstrada por dois estudos que enfatizaram a alta prevalência de saúde mental precária especialmente em áreas geográficas de população de baixa renda, como favelas, assentamentos e bairros miseráveis. Mais importante, porém, é que esses estudos comparam a saúde mental nos diversos grupos socioeconômicos, apontando as desigualdades. O artigo de Ilona Blue, neste número da Revista
Brasileira de Psiquiatria, é um exemplo disso. As características presentes em estados de pobreza que determinam uma saúde mental precária são traduzidas em um grande número de ocorrências, muitas dificuldades em longo prazo e falta de apoio da sociedade para amortecer (ou reduzir) o efeito dessas situações de estresse.

Como o meio urbano caracteriza-se por um excesso desses fatores de risco ${ }^{1}$, há uma necessidade premente de ir além da descrição da extensão do problema e realizar estudos sobre a eficácia de intervenções para melhorar a saúde mental, em especial entre mulheres de baixa renda vivendo em cidades, porque são elas que sofrem o ônus maior. Os psiquiatras precisam procurar encontrar, por um outro prisma, tipos de intervenções baseadas na comunidade que seriam mais eficazes para reduzir a precariedade da saúde mental em populações urbanas de baixa renda. A área de saúde, por meio da assistência primária, pouco tem feito para melhorar a saúde mental. Poderia ser produtivo para os psiquiatras ocuparem-se do diálogo com profissionais especialistas em desenvolvimento, envolvidos em projetos microfinanceiros (visando aumentar a renda), engenheiros ambientais que buscam soluções para melhorar as condições do meio (em especial o suprimento de água e a rede de esgotos) e, portanto, aliviar o ônus dessas populações, e assistentes sociais com experiência em fortalecer as relações sociais. Talvez uma mudança no estado de saúde mental deva ser usada regularmente como um indicador do impacto em projetos de desenvolvimento. Profissionais especialistas em desenvolvimento normalmente desconhecem seu potencial de contribuição para influir sobre a qualidade da saúde mental. Nós da área de saúde mental temos a obrigação de alertá-los sobre essa possibilidade.

Pesquisas sobre a sinergia interdisciplinar e práticas intersetoriais certamente proliferaram na nova década. Trata-se de um avanço e desafio animadores, com a abertura de várias oportunidades que devem ser tão atraentes quanto a crescente linha biológica dentro da psiquiatria.

Trudy Harpham South Bank University, London, UK

\section{Reference \\ 1. Harpham T. Urbanization and mental health in developing countries. Social Scien Med 1994;39(2):233-45.}

* Capital social pode ser definido como as normas e associações da sociedade civil que facilitam a cooperação entre cidadãos e instituições 